\title{
Osteoid Osteoma; Surgical Resection and Per-Cutaneous Radiofrequency Thermo-Ablation Outcome Comparison
}

\author{
Abdullah I. Qashgry ${ }^{1 *}$, Abdullah H. Alnemari ${ }^{2}$, Abdulaziz R. Alshehri ${ }^{2}$, \\ Alwaleed A. Alyami ${ }^{1}$, Ammar F. Qutub ${ }^{3}$, Ali H. Alyami ${ }^{1,2}$ \\ ${ }^{1}$ King Saud Bin Abdulaziz University for Health Sciences (KSAU-HS), ${ }^{2}$ King Abdulaziz Medical City, \\ National Guard Health Affairs, ${ }^{3}$ King Abdulaziz University. \\ * Corresponding Author: Abdullah Ibraheem Qashgry, Mobile No.:+966563663338, Email: Qashgry.abdullah@gmail.com
}

\begin{abstract}
Background: Oteoid osteoma is a benign bone tumor that affects mainly children and adolescents. Most patients complain of pain as the main symptom, which is usually managed by analgesia. Less commonly, the lesion can lead to bone deformity or restricted mobility. Ultimate treatment of this disease is to remove the lesion surgically, or by the recently adopted, less invasive, per-cutaneous radiofrequency thermo-ablation.

Objective of the study: To evaluate the outcome of patients diagnosed with osteoid osteoma treated with either surgical resection or per-cutaneous radiofrequency thermo-ablation (PRT).

Methods: Our data were collected during the period from January 2000 to December 2016. A total number of 28 patients who underwent either surgical resection or PRT therapy were included. We evaluated the presence of residuals after treatment, symptomatic relief, recurrence rate, and length of stay at hospital following treatment.

Results: Mean age of diagnosis in our patients was 14.7 years $( \pm 7.63)$, and 13 patients $(46 \%)$ underwent surgical treatment, and 15 had PRT therapy (54\%). The presence of post-therapy residuals, symptoms relief, and recurrence rate were not significantly different between the two treatment groups, while median length of stay post-op (surgical $=4$ days, PRT $=1$ day) was significantly different and favored PRT treatment group (p-value $=<0.001$ ).

Conclusion: PRT therapy was shown to be less invasive, safer, and significantly reduced the lengths of stay, which could be a determinant factor in fast recovery to patients and a cost-effective option.
\end{abstract}

Keywords :Osteoid osteoma, per-cutaneous radiofrequency thermo-ablation (PRT), surgical resection,surgery, ablation.

\section{INTRODUCTION}

Osteoid Osteoma is a benign tumor that occurs mainly in childhood and adolescence. However, it is not exclusive to these age groups as it may affect adults ${ }^{(1)}$. It accounts for about $11 \%$ of benign bone tumors ${ }^{(2)}$. The affected individuals mostly present with severe pain, usually dull aching in nature, that sometimes worsens at night and could affect sleep ${ }^{(1,}$ 2). This tumour is usually identified by radiological means showing signs of centrally radio-transparent ossifying lesions with a diameter less than $12-15 \mathrm{~mm}$, surrounded by a zone of reactive ossification ${ }^{(1)}$. The pain is traditionally managed conservatively by nonsteroidal anti-inflammatory drugs (NSAIDs). However, in order to achieve absolute relief, removal of this troublesome tumor is indicated. The options are mainly either surgical excision or percutaneous radiofrequency thermo-ablation (PRT) ${ }^{(2)}$.

In surgical resection, precise identification of the lesion is considered a difficulty, which usually requires wider margins resected to ensure adequate therapy. Such invasive nature, has led to higher morbidity and complications ${ }^{(3)}$. The introduction of PRT has made it the most commonly used method because of its less invasive nature, morbidity, mortality, hospital cost and stay ${ }^{(3,4)}$. Up to our knowledge, no study has compared the outcome of these two methods, therefore, our aim was to evaluate the outcome and complications of treating osteoid osteoma with either surgical resection or radiofrequency ablation at our center.

\section{METHODS}

This is a retrospective cohort study. The data were collected by reviewing the charts in the medical record department at King Abdulaziz Medical City (KAMC) in Jeddah. All the cases of osteoid osteoma were managed during the period between January 2000 to December 2016. The privacy at the time of data collection was assured. All the information and the data were anonymous, and the confidentiality was guaranteed. All data were analyzed using SPSS. Chi Square or exact Fisher test was performed for comparison of categorical variables.

A total number of 28 patients was enrolled in this study. Both genders of all ages who were diagnosed with osteoid osteoma by Computed Tomography scan (CT) were included.

In our 28 patients, 13 underwent surgical resection, and 15 were treated with Radiofrequency ablation.

Data were analyzed using SPSS version 22. Continuous variables were analyzed using mean \pm Standard Deviation (SD), and categorical variables were analyzed using frequency and percentages. 
Relation between outcome variables and exposure was conducted using chi-square test. Logistic regression model was built to adjust for the confounders in the relationship between outcome variables "recurrence" and main exposure "PRT Vs. surgical resection"

\section{RESULTS}

In this retrospective study, a total of 28 patients 'were participated, data obtained. 15 (54\%) were males, and $13(46 \%)$ were females, with an average age of diagnosis at 14.8 years $( \pm 7.63)$ (Table1) (Figure 1). Of those $28,13(46 \%)$ underwent surgical treatment, and 15 had PRT therapy (54\%) (Figure2)

Table1. Descriptive statistics for age at diagnosis of Osteoid Osteoma and lengths of stay post therapy

\begin{tabular}{|l|l|l|l|l|l|l|l|} 
& Mean & $\begin{array}{l}\text { Standard } \\
\text { Error }\end{array}$ & Median & Mode & $\begin{array}{l}\text { Standard } \\
\text { Deviation }\end{array}$ & $\begin{array}{l}\text { Sample } \\
\text { Variance }\end{array}$ & $\begin{array}{l}\text { Confidence } \\
\text { Level } \\
\mathbf{( 9 5 . 0 \% )}\end{array}$ \\
\hline $\begin{array}{l}\text { Age at } \\
\text { Diagnosis } \\
\text { (years) }\end{array}$ & 14.85185 & 1.469251 & 15 & 6 & 7.634454 & 58.28490 & \\
\hline $\begin{array}{l}\text { length of stay } \\
\text { (days) }\end{array}$ & 2.5714285 & 0.3579356 & 1 & 1 & 1.8940173 & 3.5873015 & 3.020089739 \\
\hline
\end{tabular}

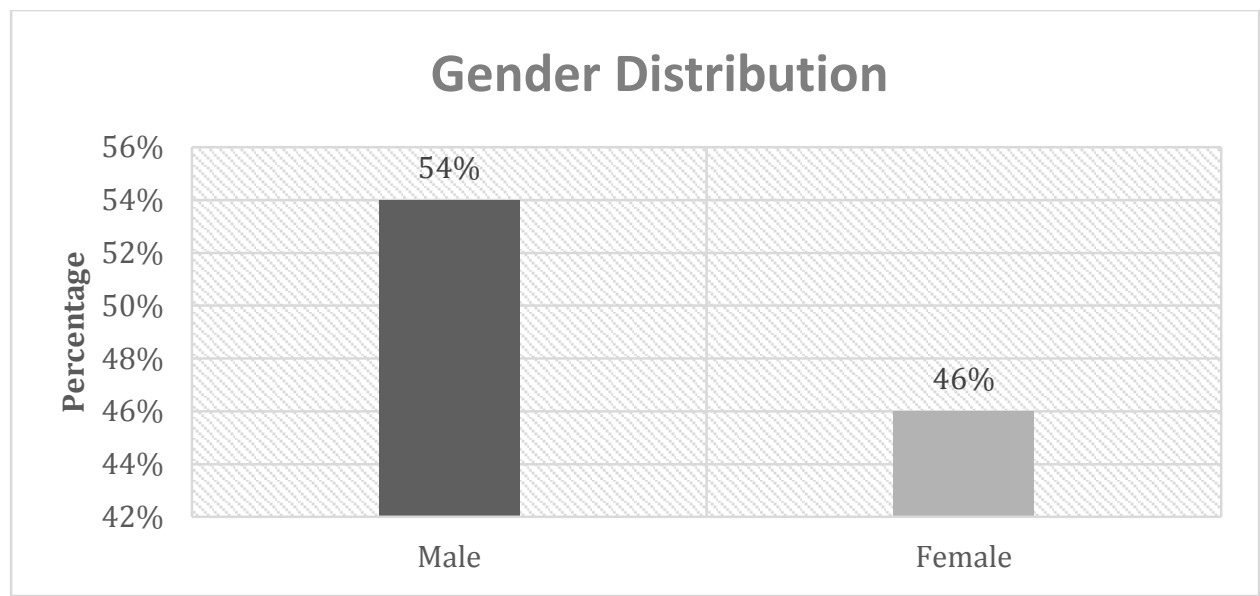

Figure1. Gender distribution among selected patients.

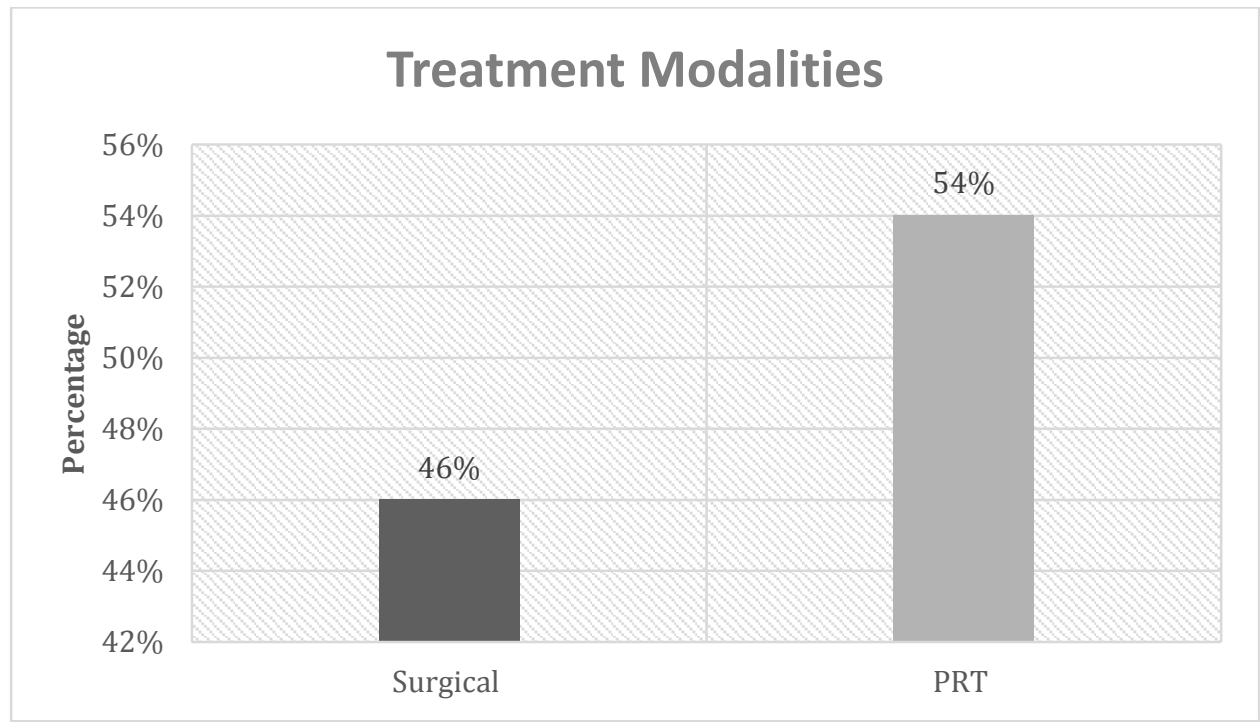

Figure2. Percentage of patients underwent either surgical resection or PRT 


\section{Procedure outcome}

Out of the 28 followed patients, only one had a residual tumor post-surgical resection. Analysis of the two treatments groups resulted in an estimated difference of -0.07 with a p-value of 0.298 , which concluded that there was no significant difference between the two groups in terms of residual identified following the procedure (Table2).

Table 2. T-test and C.I. for Two Proportions: Residual tumour

\begin{tabular}{|c|c|c|c|}
\hline Treatment & $\mathrm{X}$ & $\mathrm{n}$ & Sample p \\
\hline PRT & 0 & 15 & 0 \\
\hline Surgical & 1 & 13 & 0.076923 \\
\hline \multicolumn{4}{|c|}{ Difference $=p($ PRT $)-p($ Surgical $)$} \\
\hline \multicolumn{4}{|c|}{ Estimate for difference: -0.0769231} \\
\hline \multicolumn{4}{|c|}{ 95\% CI for difference: $(-0.221775,0.0679287)$} \\
\hline \multicolumn{4}{|c|}{$\begin{array}{l}\text { Test for difference }=0(v s \neq 0): Z=-1.04 P \text { - } \\
\text { Value }=0.298\end{array}$} \\
\hline
\end{tabular}

In terms of symptoms relief, one patient who underwent surgery with complete tumor removal was still experienced pain symptoms, and this also occurred with another patient following PRT therapy. Overall, all other patients documented complete pain relief post-surgery or ablation.

In this study, we found $29 \%$ recurrence cases compared to $71 \%$ with complete cure (Figure3). Out of the 13 patients who underwent surgical resection, 4 patients had recurrence of the tumor. On the other hand, only 3 patients from the PRT therapy group experienced recurrence.

Statistically, a Kruskal-Wallis $\mathrm{H}$ test was performed to determine if there was a difference in the median recurrence value compared to the two treatments used in our patients, surgical $(n=13)$ and PRT ( $\mathrm{n}=15)$.

The test showed that there was no statistically significant difference between the medians of the two groups, $(\mathrm{p}=0.407)(\mathrm{p}=0.290)$ respectively, in terms of recurrence rate (appendix).

Furthermore, analysis of two proportions with 95\% Confidence interval (-0.517-0.148) resulted in an estimated difference of -0.18 with a $\mathrm{p}$-value of 0.277 which also shows no significant difference in recurrence rate between the two treated groups (appendix).

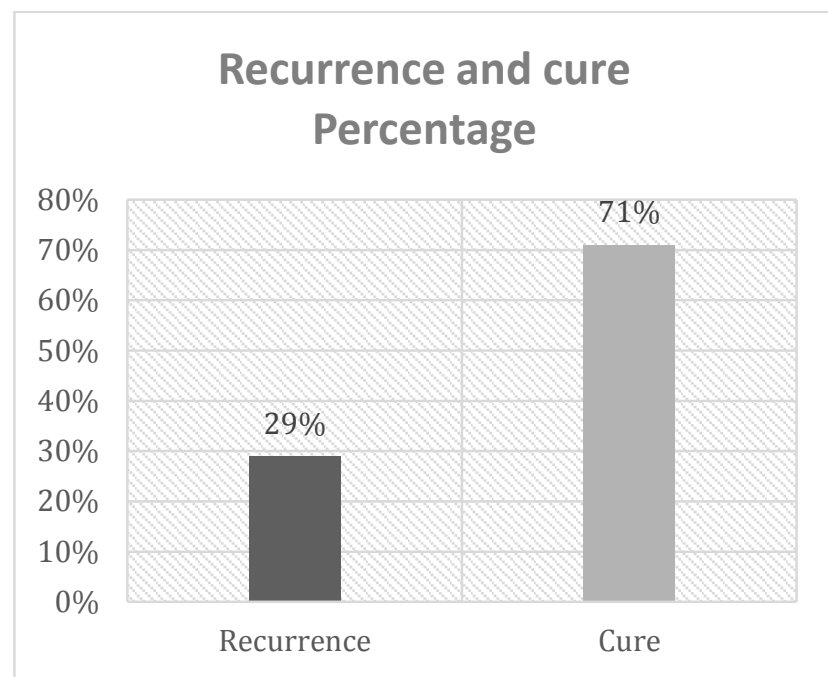

Figure 3. Recurrence and cure rate in patients treated from osteoid osteoma.

Table3. Kruskal-Wallis H Test and Two-proportion Analysis for recurrence after treatment.

\begin{tabular}{|c|}
\hline Kruskal-Wallis Test: Recurrence versus Treatment \\
\hline 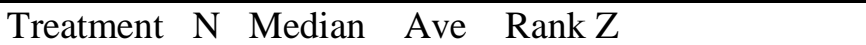 \\
\hline $\begin{array}{lllll}\text { PRT } & 15 & 0.00000 & 13.3 & -0.83\end{array}$ \\
\hline $\begin{array}{llll}13 & 0.00000 & 15.9 & 0.83\end{array}$ \\
\hline Overall $\quad 28 \quad 14.5$ \\
\hline$H=0.69 \quad D F=1 \quad P=0.407$ \\
\hline $\mathrm{H}=1.12 \mathrm{DF}=1 \mathrm{P}=0.290$ (adjusted for ties) \\
\hline $\begin{array}{l}\text { Test and CI for Two Proportions: Recurrence, } \\
\text { Treatment }\end{array}$ \\
\hline Event $=1$ \\
\hline Treatment $X$ N Sample $p$ \\
\hline $\begin{array}{llll}\text { PRT } & 3 & 15 & 0.200000\end{array}$ \\
\hline $\begin{array}{llll}\text { Surgical } & 5 & 13 & 0.384615\end{array}$ \\
\hline Difference $=p(P R T)-p($ Surgical $)$ \\
\hline Estimate for difference: -0.184615 \\
\hline 95\% CI for difference: $(-0.517655,0.148425)$ \\
\hline $\begin{array}{l}\text { Test for difference }=0(\mathrm{vs} \neq 0): Z=-1.09 \quad \mathrm{P}-\mathrm{Value}= \\
0.277\end{array}$ \\
\hline
\end{tabular}

The lengths of stay following either surgical or PRT treatment in our patients averaged 2.5 days $( \pm 1.89)$ (range 1-7 days) (Table1). In PRT treated patients, only one had stayed 5 days post-therapy, while the remaining 14 patients were discharged one day postprocedure. In contrast, only one patient was discharged on day 1 post-surgical resection compared to the other patients in this group who stayed at least 2 days or more. The Kruskal-Wallis test in this case was done to determine any difference in the median length of stay between the two groups; surgical $(\mathrm{n}=13$, median=4.0), and PRT $(\mathrm{n}=15$, median=1.0). Results showed a significant difference ( $p$-value $=$ $<0.001)$ between the two groups with regards to the lengths of stay in the hospital following treatment (Table 4). 
Table 4. Kruskal-Wallis Test: length of stay versus Treatment

\begin{tabular}{|lcccc|}
\hline Treatment & N Median & Ave & Rank Z \\
PRT & 15 & 1.000 & 9.1 & -3.71 \\
Surgical & 13 & 4.000 & 20.7 & 3.71 \\
Overall & 28 & \multicolumn{4}{c|}{14.5} \\
$\mathrm{H}=13.75$ & $\mathrm{DF}=1 \quad \mathrm{P}=0.001$ \\
$\mathrm{H}=16.45$ & $\mathrm{DF}=1 \quad \mathrm{P}=0.001 \quad$ (adjusted for ties) \\
\hline
\end{tabular}

\section{DISCUSSION}

Osteoid osteoma is a benign skeletal tumor that is managed primarily for the eradication of pain. The main options of treatment consisted of surgical excision and percutaneous radiofrequency thermoablation (PRT). Surgical excision can be done through either curettage of the lesion or en-bloc resection. This option is considered to be more invasive when compared with PRT. The latter is considered to be a safer, less invasive, and effective option ${ }^{(2,3)}$. Although osteoid osteoma is not a very common disease, we were able to obtain data from 28 patients during the period from 2000-2016, which is relatively a low number. However, all our patients were confirmed with the diagnosis by CT scan. Nonetheless, gender distribution was not significantly favoring a gender according to our study, and mean age of diagnosis was 14.7 years which favors the common age range of this disease manifestation ${ }^{(2)}$.

In terms of symptomatic relief, we have observed that the reported analytical difference between the two groups was not significant. Recurrence rate was also not significant when comparison was done between the two groups. Although overall we observed a $29 \%$ recurrence in our population, which indicate that regardless of treatment, some patients may experience such outcome. In a study done by Elian et al., they reported repeating RFA in two out of 15 patients due to non-resolution of their condition ${ }^{(3)}$, which also supports our findings that there was a degree of recurrence in managing this disease. Furthermore, Rosenthal et al. compared the rate of recurrence between the two methods and concluded that no significance was observed in recurrence rate ${ }^{(5)}$. However, it is important to mention that recurrence might be due to minute residuals that were not detected nor resected or ablated, or these technicalities must be addressed in future studies to have better assessment of this disease's outcome.

Length of hospital stay was less with patients who underwent PRT in comparison with patients who were treated by surgical excision. One patient out of the 15 patients who were managed by PRT stayed for 5 days after the procedure while the remaining patients were discharged one day following the procedure, with our average being 1.3 days. Sung et al., reported their patients' average hospital stay of 1.8 days which was more compared to our result ${ }^{(6)}$. This signifies the advantage of this approach compared to surgical-resection for these patients, in a sense that they become mobile early and return to normal dailyliving sooner. In addition, this approach might be more cost effective due to the less time patients spend in the hospital post-procedure ${ }^{(3,7)}$.

Limitation of our study was the small number of patients and the fact that our study was retrospective. More follow-up studies should be conducted to evaluate the recurrence rate on the long term. Another limitation is the ambiguity between residual tumors and recurrence. Additional studies should be done in order to accurately confirm complete resection or ablation and whether the detected lesion is new onset or minute residuals that manifested.

To conclude, in our retrospective study comparing the outcome between surgical resection and PRT treatment in osteoid osteoma patients, percutaneous radiofrequency thermo-ablation proved to be less invasive and safer. More importantly, PRT approach had significantly less length of stay which could facilitate quicker recovery to our patients and might be of great value in terms of cost effectiveness compared to conventional surgery. Further follow up would bring about more reliable assessment of the outcome of treating this disease.

\section{REFERENCES}

1. Noordin S, Allana S, Hilal K, Nadeem N, Lakdawka R, Sadruddin A, Uddin N(2018): Osteoid osteoma: Contemporary management. Orthopedic reviews,10(3).

2. Papathanassiou ZG, Megas P, Petsas T, Papachristou DJ, Nilas J, Siablis D(2008): Osteoid osteoma: Diagnosis and treatment. Orthopedics,31:11.

3. Elian MMM, Sadek AF(2015): What makes CT guided radiofrequency ablation for osteoid osteoma superior to open surgery in terms of pain control and patient's quality of life? The Egyptian Journal of Radiology and Nuclear Medicine,46(4):949-55.

4. Motamedi D, Learch TJ, Ishimitsu DN, Motamedi K, Katz MD, Brien EW et al.(2009): Thermal ablation of osteoid osteoma: Overview and step-by-step guide 1.Radiographics,29(7):2127-41.

5. Rosenthal DI, Hornicek FJ, Wolfe MW, Jennings LC, Gebhardt MC, Mankin HJ(1998): Percutaneous radiofrequency coagulation of osteoid osteoma compared with operative treatment. J Bone Joint Surg Am.,80(6):815-21.

6. Sung K-S, Seo J-G, Shim JS, Lee YS(2009): Computedtomography-guided percutaneous radiofrequency thermoablation for the treatment of osteoid osteoma-2 to 5 years follow-up. International orthopaedics,33(1):215-8.

7. Gebauer B, Collettini F, Bruger C, Schaser K, Melcher I, Tunn P et al.(2013):Radiofrequency ablation of osteoid osteomas: analgesia and patient satisfaction in long-term follow-up.

connect.com/products/.../10.../s-0033-1350347 